<smiles>[O]</smiles>

ценка знаний студентов Новосибирска в вопросах профилактики ВИЧ-инфекции и Аругих ИППП

Хрянин А.А. ${ }^{1,2}$, Шпикс Т.А. ${ }^{1}$, Русских М.В. ${ }^{1}$, Бочарова В.К. ${ }^{1}$

\footnotetext{
1 ФГБОУ ВО «Новосибирский государственный медицинский университет» Минздрава России

630091, Россия, г. Новосибирск, Красный пр., д. 52

${ }^{2}$ РО0 «Ассоциация акушеров-гинекологов и дерматовенерологов»

630004, Россия, г. Новосибирск, ул. Ленина, д. 55
}

В статье представлены данные опроса 394 студентов как медицинского вуза, так и непрофильных учреждений г. Новосибирска с целью оценки уровня информированности по вопросам профилактики и рискованного полового поведения в отношении ВИЧ-инфекции и ИППП. Полученные данные свидетельствуют о недостаточной информированности молодых людей в отношении ВИЧ/ИППП. Студенты показали низкую настороженность в отношении своей собственной безопасности. Выявлена высокая степень коммуникативной толерантности у студентов. Установлены терпимость студентов к дискомфортным состояниям партнера по общению, недостаток в умении скрывать или сглаживать свои отрицательные эмоции, возникающие при столкновении с некоммуникабельными качествами у партнера.

Ключевые слова: вич-инфекция, иппп, профилактика, студенты, информированность, коммуникативная толерантность, рискованное половое поведение.

Конфрликт интересов: авторы заявляют об отсутствии потенциального конфрликта интересов, требующего раскрытия в данной статье.

Для цитирования: Хрянин А.А., Шпикс Т.А., Русских М.В., Бочарова В.К. Оценка знаний студентов Новосибирска в вопросах профилактики ВИЧ-инфекции и других ИППП. Вестник дерматологии и венерологии. 2020; 96 (3): 34-42. https://doi.org/10.25208/vdv1142 


\title{
A - ssessment of knowledge of Novosibirsk students in the prevention of HIV infection and other STIs
}

\author{
Aleksey A. Khryanin ${ }^{1,2}$, Tatyana A. Shpiks', Maria V. Russkih ${ }^{1}$, Valentina K. Bocharova ${ }^{1}$
}

\author{
${ }^{1}$ Novosibirsk State Medical University \\ Krasny pr., 52, Novosibirsk, 630091, Russia \\ ${ }^{2}$ Association Obstetricians-Gynecologists and Dermatovenerologists \\ Lenina str., 55, Novosibirsk, 630004, Russia
}

The article presents information about a survey of 394 students from medical university and nonspecialized institutions in Novosibirsk, in order to analyze the level of awareness about risky sexual behavior and prevention of HIV infection and STIs. The obtained information indicates a lack of awareness among young people about HIV/STIs. Students showed low alertness about their own safety. There was revealed a high degree of communicative tolerance among students. It was established, that students have a sense of tolerance for the uncomfortable feelings of the partner during communication, and the lack of ability to hide their negative emotions about non-communicative qualities of the partner.

Keywords: HIV infection, STIs, prevention, students, awareness, communication tolerance, risky sexual behavior.

Conflict of interest: the authors state that there is no potential conflict of interest requiring disclosure in this article.

For citation: Aleksey A. Khryanin, Tatyana A. Shpiks, Maria V. Russkih, Valentina K. Bocharova. A new assessment of knowledge of Novosibirsk students in the prevention of HIV infection and other STIs. Vestnik Dermatologii i Venerologii. 2020; 96 (3): 34-42. https://doi.org/10.25208/vdv1142 
Введение. С 1987 г. идет неуклонный рост числа людей, инфицированных ВИЧ. В России число инфиицированных уже давно преодолело отметку в миллион человек. Основным путем передачи ВИЧ-инфекции на данный момент является гетеросексуальный половой контакт. Особенно важными в сложившейся ситуации являются массовая пропаганда и обучение населения, в частности молодых людей, будущего нашей страны. Студенты являются социально активной частью населения, соответственно находятся в группе риска по заболеваемости ИППП/ВИЧ. Поэтому оценка инфрормированности молодых людей о ВИЧ-инфекции и ИППП крайне необходима.

Материалы и методы. С целью изучения информированности о ВИЧ/ИППП был проведен социологический опрос среди 1-го курса НГМУ, 1-го курса НКПИ (Новосибирский колледж парикмахерского искусства) и студентов 1-го курса НАК (Новосибирский аграрный колледж) в виде анонимного анкетирования с закрытыми вопросами (с подписанием добровольного инорормированного согласия). Для опроса была использована анкета, состоящая из 23 вопросов, разработанная сотрудниками кафедры дерматовенерологии ПСПбГМУ им. акад. И.П. Павлова и Центра социологии девиантности и социального контроля Института социологии РАН, адаптированная авторами. Для выявления психологических особенностей студентов, которые могут оказывать влияние на поведение, склонность к риску, отношение к болезни, была применена методика оценки уровня коммуникативной толерантности В.В. Бойко. Опросник В.В. Бойко состоит из 45 вопросов-утверждений, сгруппированных в 9 шкал. Респонденты должны были оценить, насколько данные утверждения верны по отношению к ним, используя баллы от 0 до 3. Чем больше набрано баллов, тем ниже степень толерантности. Максимальное количество баллов, которое можно набрать, ответив на все вопросы анкеты, - 135; максимальное количество баллов за каждую из шкал - 15 (табл. 1).

Шкала 1. Неприятие или непонимание индивидуальности человека.

Шкала 2. Использование себя в качестве эталона при оценках других.
Шкала 3. Категоричность или консерватизм в оценках людей.

Шкала 4. Неумение скрывать или сглаживать неприятные чувства.

Шкала 5. Стремление переделать, перевоспитать партнера по общению.

Шкала 6. Стремление подогнать других под себя.

Шкала 7. Неумение прощать другому человеку его ошибки.

Шкала 8. Нетерпимость к дискомфортным (болезнь, усталость, отсутствие настроения) состояниям партнера по общению.

Шкала 9. Неумение приспосабливаться к другим участникам общения.

Статистический анализ проведен с использованием программ Microsoft Excel и SPSS. Использованы критерии хи-квадрат, стандартные статистические методы.

Результаты. В анкетировании приняли участие 394 студента: из них 202 человека - 1-го курса НГМУ (юноши - 33,5\%, девушки - 66,5\%), 103 человека - 1-го курса колледжа парикмахерского искусства и 89 человек из аграрного колледжа (юноши - 17,1\% и девушки - 82,9\%). Средний возраст респондентов из НГМУ составил 18,5 года, средний возраст респондентов из НКПИ и НАК составил 16,5 года.

Анкета, посвященная информированности о ВИЧ/ ИППП, состояла из двух частей. Первая часть анкеты содержала вопросы, характеризующие знания студентов о путях передачи ВИЧ-инфекции и методах профилактики. Большинство учащихся (70-77\%) всех образовательных учреждений предпочитают получать информацию о половой жизни из сети Интернет, а также в ходе обсуждения волнующих вопросов с друзьями (60-67\%) (рис. 1). Довольно популярными среди учащихся колледжей оказались беседы с родителями (47$50 \%$ ), а также беседы с врачом (36-39\%), в то время как студенты-медики, наоборот, предпочитают обсуждать эти вопросы в первую очередь с врачом (44\%), нежели с родителями (33\%). Обсуждать вопросы половой жизни со своими половыми партнерами предпочитают 22-29\% студентов колледжей и $32 \%$ студентов НГМУ.

Студенты непрофрильных образовательных учреждений достаточно хорошо осведомлены о путях переда-

\begin{tabular}{|c|c|c|c|c|c|}
\hline & \multirow{2}{*}{ Вариант передачи } & \multirow{2}{*}{ Верный ответ } & \multicolumn{3}{|c|}{ \% правильных ответов } \\
\hline & & & НКПИ & HAK & НГМу \\
\hline 1 & Через поцелуй & Нет & 91 & 88 & 85 \\
\hline 2 & Делая татуировку & Да & 91 & 79 & 84 \\
\hline 3 & Через рукопожатия & Нет & 99 & 97 & 99 \\
\hline 4 & Через сиденье унитаза & Нет & 89 & 88 & 93 \\
\hline 5 & Через укусы комаров & Нет & 76 & 44 & 78 \\
\hline 6 & Через половой контакт & Да & 99 & 99 & 98 \\
\hline 7 & Использование общего шприца при введении наркотиков & Да & 94 & 92 & 96 \\
\hline 8 & При кормлении грудью & Да & 52 & 47 & 46 \\
\hline 9 & При орально-генитальных контактах & Да & 60 & 53 & 58 \\
\hline
\end{tabular}




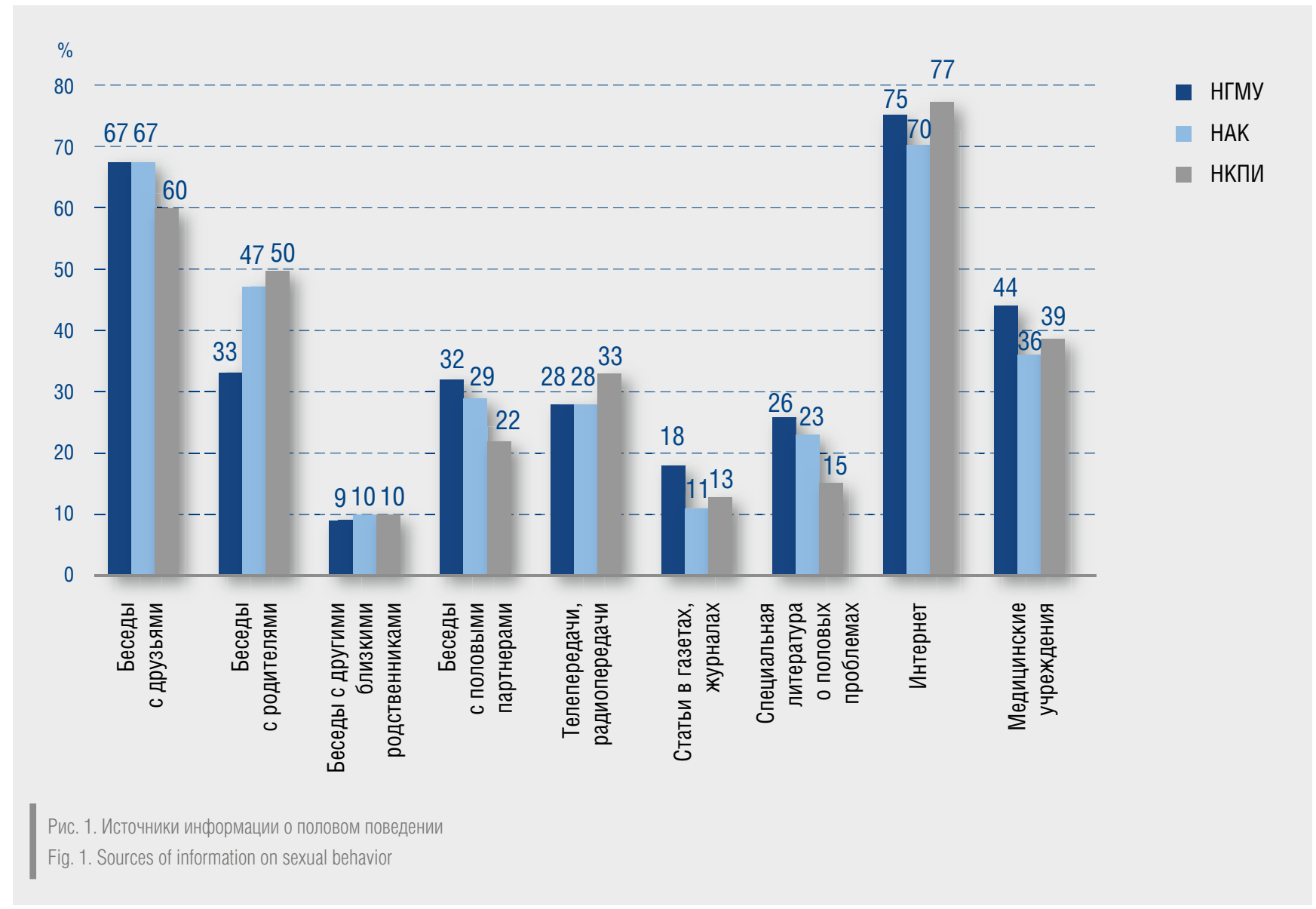

чи ВИЧ-инфекции, за исключением двух утверждений, касающихся передачи вируса при грудном вскармливании и при орально-генитальных контактах. Однако настораживает тот фракт, что больше половины студентов НАК считают, что вирус ВИЧ может передаваться через укусы насекомых. Осведомленность о путях передачи ВИЧ-инфекции у студентов-медиков также хорошая, но смущает, что только половина студентов знают о том, что ВИЧ может передаваться с грудным молоком (46\%) и при орально-генитальных контактах (58\%) (табл. 2).

Достаточную информированность показали большинство учащихся всех образовательных учреждений в вопросе, касающемся выбора контрацептива, который может защитить от половых инфекций, в том числе ВИЧ (табл. 3). Так, правильный ответ «презерватив» выбрали 87-95\%, что действительно является доступным и эфффективным способом профилактики ВИЧ и ИППП. Однако обращает на себя внимание низкий уровень информированности студентов, в том числе медицинского университета, в вопросах профилактики венерических заболеваний. Так, многие считают, что комбинированные оральные контрацептивы, внутриматочная спираль, прерванный половой акт, гормональное кольцо могут являться средством защиты от инфицирования.

Только 73-83\% студентов знают, что презерватив защищает от ВИЧ/СПИДа, и 22-31\% уверены в том, что заражение возможно у людей, которые имеют большое количество половых партнеров (табл. 4). Кроме того, $10-17 \%$ респондентов имеют ложное представле-

Таблица 2. Осведомленность студентов о защите от половых инфекций (ИППП), в том числе ВИЧ

Table 2. Student awareness about protection against sexually transmitted infections (STIs), including HIV

\begin{tabular}{cccc}
\hline Варианты ответа & HГМу, $\%$ & HКПи, $\%$ & HАК, $\%$ \\
\hline 1. Презервативы & 95 & 94 & 87 \\
\hline 2. Комбинированные оральные контрацептивы (таблетки) & 8 & 10 & 12 \\
\hline 3. Внутриматочная спираль & 8,5 & 2 \\
\hline 4. Гормональное кольцо & 4 & 2 \\
\hline 5. Прерванный половой акт & 4 & 3 \\
\hline
\end{tabular}


Таблица 3. Осведомленность студентов о ВИч/СПИДе в целом (процент правильных ответов)

Table 3. Student awareness about HIV/AIDS in general (percentage of correct answers)

\begin{tabular}{|c|c|c|c|}
\hline & нгМУ, \% & НКПИ, \% & HAK, \% \\
\hline \multirow{2}{*}{$\begin{array}{l}\text { 1. ВИЧ/СпИДом заражаются только } \\
\text { гомосексуалисты и наркоманы }\end{array}$} & \multicolumn{3}{|c|}{ Не согласен } \\
\hline & 90 & 83 & 92 \\
\hline \multirow{2}{*}{$\begin{array}{l}\text { 2. Чтобы заразиться ВИЧ/СПИДом, } \\
\text { нужно иметь много половых партнеров }\end{array}$} & \multicolumn{3}{|c|}{ Не согласен } \\
\hline & 69 & 70 & 78 \\
\hline \multirow{2}{*}{$\begin{array}{l}\text { 3. По внешнему виду человека можно } \\
\text { определить, болен человек ВИЧ/СПИДом или нет }\end{array}$} & \multicolumn{3}{|c|}{ Не согласен } \\
\hline & 89 & 84 & 91 \\
\hline \multirow{2}{*}{$\begin{array}{l}\text { 4. Существует анализ крови, } \\
\text { по которому можно определить, } \\
\text { болен человек ВИЧ/СПИДом или нет }\end{array}$} & \multicolumn{3}{|c|}{ Согласен } \\
\hline & 97 & 98 & 99 \\
\hline \multirow{2}{*}{$\begin{array}{l}\text { 5. Использование презервативов } \\
\text { может предотвратить заражение ВИЧ/СпИДом }\end{array}$} & \multicolumn{3}{|c|}{ Согласен } \\
\hline & 83 & 85 & 73 \\
\hline \multirow{2}{*}{$\begin{array}{l}\text { 6. Заболевшего ВИЧ/СпИДом } \\
\text { можно вылечить современными лекарствами }\end{array}$} & \multicolumn{3}{|c|}{ Не согласен } \\
\hline & 74 & 64 & 53 \\
\hline \multirow{2}{*}{$\begin{array}{c}\text { 7. Прерванный половой акт может защитить } \\
\text { от заражения ВИЧ/СПИДом }\end{array}$} & \multicolumn{3}{|c|}{ Не согласен } \\
\hline & 84 & 87 & 87 \\
\hline
\end{tabular}

Таблица 4. Распределение ответов респондентов на вопрос, связанный с использованием презерватива (в процентах)

Table 4. Distribution of respondents' answers to the question related to condom use (percentage)

\begin{tabular}{|c|c|c|c|c|}
\hline & Как часто вы используете презерватив? & нКпИ, \% & HAK, \% & нгму, \% \\
\hline 1 & Всегда & 34 & 34 & 42 \\
\hline 2 & В большинстве случаев & 27 & 37 & 33 \\
\hline 3 & Иногда & 13 & 18 & 11 \\
\hline 4 & Редко & 18 & 8 & 11 \\
\hline 5 & Никогда & 2 & 3 & 4 \\
\hline
\end{tabular}

ние о том, что ВИЧ/СПИДом заражаются только определенные социальные группы населения (гомосексуалисты, наркоманы).

В среднем 53\% респондентов всех образовательных учреждений считают недостаточно освещенной проблему ВИЧ/СПИДа в г. Новосибирске.

Вторая часть анкеты посвящена вопросам рискованного сексуального поведения студентов. Примерно половина всех студентов уже живет половой жизнью (42\% студентов аграрного колледжа и колледжа парикмахерского искусства и 51\% учащихся медицинского университета), средний возраст начала половой жизни 15,5 года среди студентов колледжей и 16,5 года среди студентов НГМУ. Основным мотивом у молодых людей к вступлению в сексуальные отношения является любовь (66\% НАК, 73\% НКПИ и 70\% студентов НГМУ), на втором месте оказалось половое влечение - его выбрали $9 \%$ НКПИ, 30\% НАК и 32\% студентов НГМУ. Третье место среди причин начала половой жизни заняло любопытство (НАК - 13\%, НКПИ - 4\%, НГМУ - 13,6\%), а также алкогольное/наркотическое опьянение (HАK $11 \%$, НКПИ - 4\%, НГМУ - 4\%). Очень важно обратить внимание на то, что 2,3\% студентов НКПИ признались, что для них причиной вступления в половую связь явилось насилие, в то время как обучающиеся аграрного колледжа не указывали данную причину вовсе, а студенты НГМУ лишь в 0,5\%.

Большинство учащихся колледжей (НАK - 60\%, НКПИ - 67\%) указали, что у них имеется постоянный половой партнер, среди студентов НГМУ постоянный половой партнер имеется у 52\% опрошенных. Среднее число половых партнеров у учащихся колледжа парикмахерского искусства на момент опроса составило 5 человек, у аграрного - 2,5 человека, а у студентов НГМУ - 3,2 человека. Тревожным является факт, что половые контакты с лицами одного пола имели 8 и $18 \%$ студентов НАК и НКПИ соответственно и $5 \%$ студентов медицинского университета. Кроме того, в половой контакт с малознакомыми людьми вступали как учащиеся колледжей (НАК - 16\%, НКПИ - 12\%), 
так и студенты медицинского университета (15\%). При этом студенты аграрного колледжа указали, что вступали в интимные отношения с малознакомыми людьми во всех случаях под действием алкогольного/ наркотического опьянения. Обучающиеся парикмахерского колледжа и медицинского университета имели половую связь под воздействием алкогольного/наркотического опьянения в 2,5 и $3 \%$ соответственно.

Немаловажным был анализ ответов студентов на вопрос использования презервативов во время полового акта. В целом практически половина студентов колледжей (НКПИ - 30\%, НАК - 50\%) призналась в том, что им не нравится использовать презерватив. Хотя часть студентов считают, что использование презерватива может усилить приятные ощущения (НКПИ - 44\%, НАК - 68\%), среди основных причин отказа от него студенты колледжей указали тот факт, что использование презерватива нарушает ход сексуальных отношений (НКПИ - 14\%, НАК - 16\%) и мешает полностью насладиться сексом (НКПИ - 35\%, НАК - 68\%). При этом учащиеся колледжа парикмахерского искусства в 76\% ответов считают презерватив надежным методом защиты от ИППП и ВИЧ, в то время как респонденты аграрного колледжа - в 32\% ответов. Одна треть студентов-медиков (34\%) также заявила о том, что им не нравится использовать презерватив, и половина студентов (47\%) считает, что с презервативом нельзя полностью насладиться сексом. Почти 20\% студентов-медиков уверены, если партнер предлагает использовать презерватив, значит, он болен. Удивительно, что 20\% студентов-медиков считают, что презерватив не является надежным средством защиты от ВИЧ и ИППП.
Поразителен тот факт, что при каждом занятии сексом используют презерватив только 34\% студентов колледжей и $42 \%$ студентов-медиков. Учащиеся колледжей (НКПИ - 2\%, НАК - 3\%) и 4\% студентов медицинского университета никогда не используют презерватив (табл. 5). При этом практически все студенты образовательных учреждений подтвердили, что у них не было ИППП в анамнезе (97,5\% учащихся колледжей и $99 \%$ студентов НГМУ). Чаще всего студенты используют презерватив при вагинальном сексе (НКПИ - 46\%, НАК - 42\% и НГМУ - 53\%), при анальном прибегают к его использованию 26\% учащихся НАК, $13 \%$ - НКПИ и $11 \%$ учащихся НГМУ, а при оральном - НКПИ - 5\%, НАК - 16\% и НГМУ - 10\%.

Для оценки коммуникативной толерантности студентов колледжей была использована методика В.В. Бойко.

Половина студентов как аграрного, так и парикмахерского колледжей продемонстрировала высокий уровень толерантности (рис. 2) по отношению к окружающим, в том числе и к ВИЧ-инсрицированным больным. Это важный показатель развития общества и того, насколько оно готово принять таких больных и сосуществовать с ними, не прибегая к дискриминации. В одном из наших исследований, посвященных изучению коммуникативной толерантности у будущих врачей, мы также оценивали данный показатель среди студентов 4-го курса НГМУ, где опрошенные также показали высокий уровень коммуникативной толерантности [1].

Набранные баллы по отдельным шкалам опросника Бойко студентами аграрного и парикмахерского колледжей оказались также в целом на среднем уров-

\begin{tabular}{ccc}
\hline Высокая степень толерантности & Средняя степень & Низкая степень \\
\hline $1-45$ баллов & $45-85$ баллов & $85-125$ баллов \\
\hline
\end{tabular}

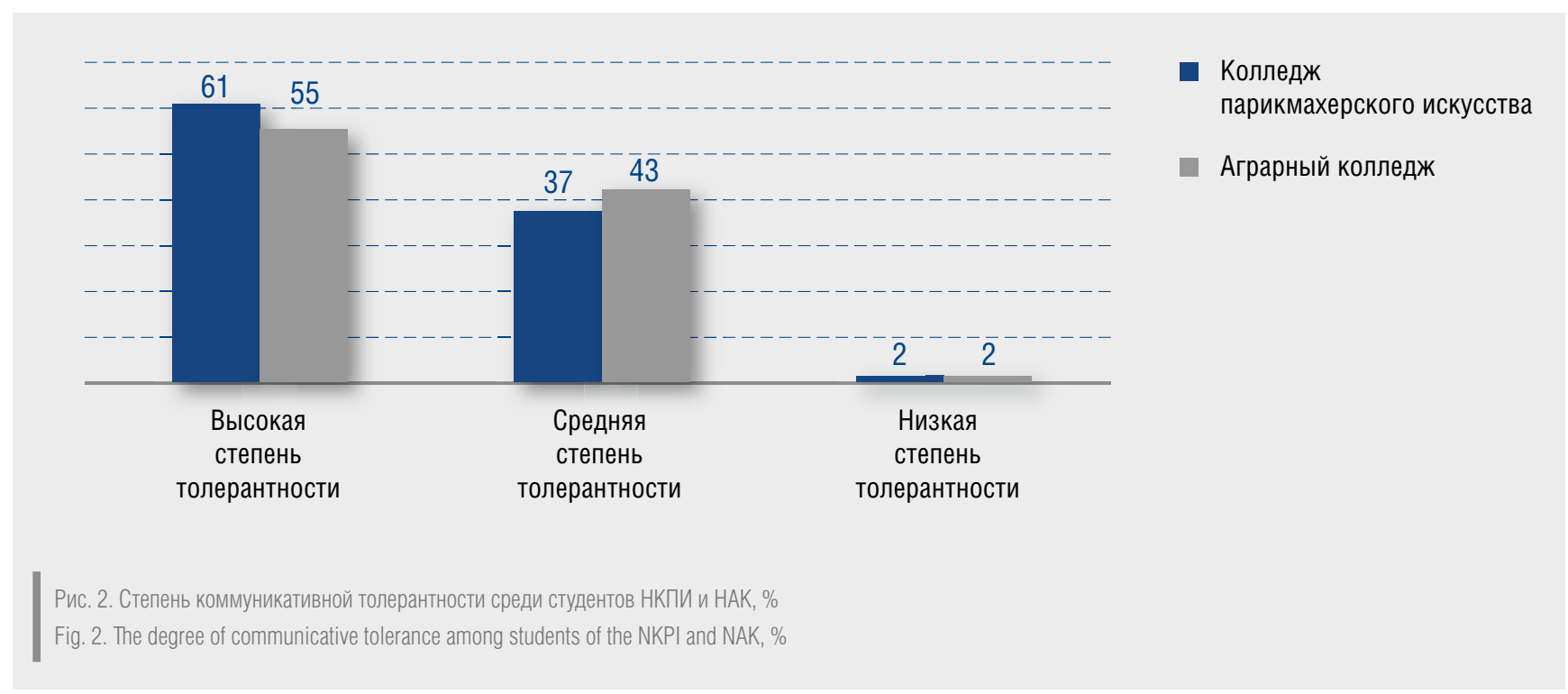


не (табл. 6), что говорит о хорошей коммуникативной толерантности по всем показателям. Однако мы обратили внимание на шкалы, где респонденты набрали больше баллов, и те, где баллов было меньше, и получили следующее: наиболее низкие баллы студенты набрали по восьмой и второй шкалам, что указывает на их терпимость к дискомфортным состояниям партнера по общению (болезнь, усталость, плохое настроение), у студентов нет тенденции при оценке поведения, образа мыслей партнера по общению рассматривать себя в качестве эталона; с другой стороны, более высокие баллы по четвертой и шестой шкалам говорят о таких качествах, как неумение скрывать или сглаживать неприятные чувства, возникающие при столкновении с некоммуникабельными качествами у партнеров, и стремление подогнать других участников коммуникации под себя: к своим привычкам и притязаниям.

Обсуждение. Полученные данные свидетельствуют о недостаточной информированности молодых людей в отношении ВИЧ/ИППП. Опрошенные показали свои заблуждения в отношении передачи ВИЧ с грудным молоком и при орально-генитальных контактах, чего не ожидалось от студентов медицинского университета, но это, видимо, связано с началом их пути в медицине и отсутствием некоторых знаний на первых этапах обучения.

В своей будущей работе мы планируем остановиться на психологической части исследования более детально. Это связано с тем, что за фрасадом недостаточной осведомленности студентов в отношении отдельных вопросов, касающихся ВИЧ/ИППП, а также за проявлениями рискованного поведения могут скрываться психологические причины, например отрицание опасности или нежелание задумываться над неприятными вопросами, что может быть, в свою очередь, связано с присутствием у студентов психологических механизмов защиты (вытеснение, проекция, идентификация и др.), снимающих состояние глубинной подсознательной тревоги, которая не распознается на уровне сознания. Современный быстро меняющийся мир создает условия хронического стресса с возникновением у людей эмоциональных нарушений в фрорме общего психологического дискомфорта, депрессии, свободно плавающей тревоги. Игнорирование реальной опасности, избегающее или рискованное поведение на этом фоне становятся «методом выбора» в фрорме психологической защиты, позволяющей временно отвлечься от психотравмирующей реальности. Знание психологических причин рискованного поведения молодежи может быть использовано в создании эфффективных методов профилактики.

В подобном исследовании, проводившемся в г. Новосибирске в 2018 г., было опрошено более 1000 студентов, обучающихся как в медицинском, так и в других университетах. Данные, полученные в результате опроса студентов, практически не отличаются от тех, что получены в настоящем исследовании, что в очередной раз доказывает необходимость работы с молодежью в целях увеличения уровня их осведомленности о ВИЧ и других ИППП [2].

В исследовании, проведенном в Шотландии, установлено, что расширение знаний об ИППП необходимо, но недостаточно для изменения поведения, так как надо учитывать и другие факторы, способствующие здоровьесберегающему поведению (например, анализ собственных рисков, социальное давление и определенные социальные нормы и правила, принятые в обществе) [3].

Поэтому для уменьшения количества молодых людей, склонных к рискованному половому поведению, а также их приверженности к тестированию на ИППП, необходимо не только обеспечивать насе-

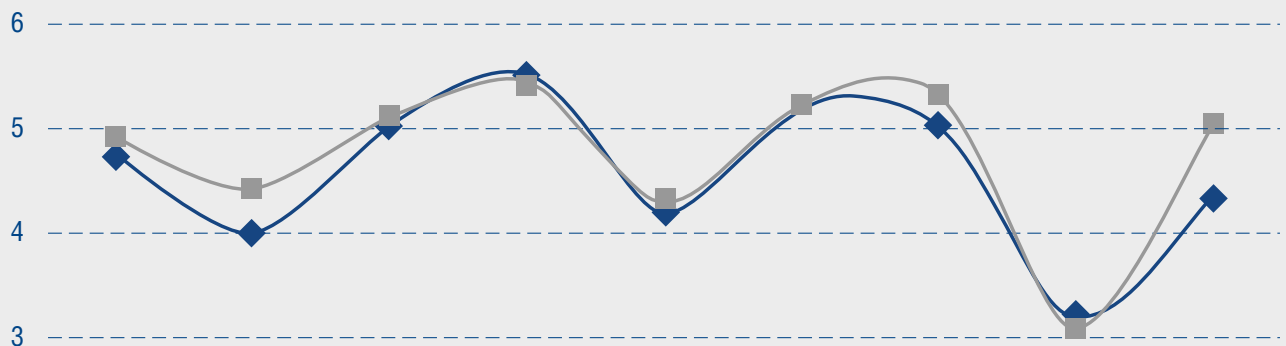

3

\begin{tabular}{|c|c|c|c|c|c|c|c|c|c|}
\hline & Шкала 1 & Шкала 2 & Шкала 3 & Шкала 4 & Шкала 5 & Шкала 6 & Шкала 7 & Шкала 8 & Шкала 9 \\
\hline - Средний балл по шкале (НГПИ) & 4,7 & 4 & 5 & 5,5 & 4,2 & 5,2 & 5 & 3,2 & 4,3 \\
\hline - - Средний балл по шкале (НАК) & 4,9 & 4,4 & 5,1 & 5,4 & 4,3 & 5,2 & 5,3 & 3,1 & 5 \\
\hline
\end{tabular}


ление доступной информацией, но и создавать социально-этические нормы верного поведения.

В то время как уровень знаний о ВИЧ-инфекции постепенно улучшается, о других ИППП все так же не принято говорить, что создает определенный пробел в осведомленности молодого населения.

Примером может послужить кампания, проводимая в колледжах Соединенных Штатов Америки под названием GYT (get yourself tested). Кампания GYT предоставляла колледжам и университетам США возможность достичь целей «здорового кампуса 2020», уделяя приоритетное внимание осведомленности об ИППП и тестированию студентов в своих кампусах, снижая стигматизацию вокруг тестирования на ИППП и предоставляя колледжам и университетам информационные и рекламные материалы [4]. Благодаря данной кампании больше половины студентов обратилось за тестированием на ИППП впервые в жизни.

Таким образом, возникает необходимость совершенствования методов первичной профилактики ИППП среди молодых людей. Данные методы должны соответствовать последним тенденциям технического прогресса и иметь максимальный охват целевой аудитории. Источники получения знаний о сохранении своего здоровья должны быть доступны и учитывать интересы современных подростков. В этом случае достаточный уровень информированности среди молодежи приведет к снижению рисков заражения ИППП и ВИЧ-инфекции.

Выводы. Студенты показали низкую настороженность в отношении своей собственной безопасности. Возможно, это связано с их юным возрастом и, как многие из них указали, недостаточным освещением данной проблемы, из-за чего принято считать, что эта проблема никогда не коснется непосредственно каждого из них. Раннее начало половой жизни, неразборчивость при выборе полового партнера, вступление в интимные отношения под действием алкогольного опьянения, однополые контакты - все это как проявление рискованного сексуального поведения указывает на высокий риск заражения ИППП, в том числе ВИЧ-инфекцией.

Психологическое исследование обнаружило достаточно высокую толерантность респондентов, проявляемую ими в общении. Особенно ярко выступает терпимость студентов к дискомфортным состояниям партнера по общению (болезнь, усталость, плохое настроение). Это качество может явиться хорошей основой для дальнейшей работы с молодежью с целью фрормирования здорового образа жизни. Однако обращает на себя внимание выявленный недостаток в умении респондентов скрывать или сглаживать свои неприятные чувства, возникающие при столкновении с некоммуникабельными качествами у партнеров, что может приводить к конфрликтным ситуациям, поэтому эта психологическая черта в определенных случаях требует коррекции. Психологические особенности человека, несомненно, влияют на его поведение в целом, на склонность к рискованному или осторожному, разумному поведению; внимательное отношение к своему здоровью и здоровью окружающих или игнорирование информации, которая могла бы предотвратить опасные болезни. Поэтому мы планируем более детальное исследование индивидуальных психологических особенностей студентов в контексте рискованного полового поведения молодежи.

Авторы выражают искреннюю признательность и благодарность за помощь в организации проведения социологического опроса студентов: ректору НГМУ профессору И.О. Маринкину, главному внештатному специалисту Министерства здравоохранения Новосибирской области по гигиене детей и подростков и школьной медицине к.м.н. А.С. Фунтикову, клиническим ординаторам кафедры дерматовенеролоии и косметологии НГМУ М.А. Литохиной и Ф.А. Сухареву.

\section{Литература/References}

1. Хрянин А.А., Решетников О.В., Шпикс Т.А., Бочарова В.К., Русских М.В., Маринкин И.О. Отношение студентов-медиков к ВИЧ-инфиццированным: страх или помощь? Вестник дерматологии и венерологии. 2019; 95 (4): 40-47. https://doi.org/10.25208/0042-4609-2019-95-4-40-47. [Khryanin A.A., Reshetnikov 0.V., Shpiks T.A., Bocharova V.K., Russkikh M.V., Marinkin I.O. The attitude of medical students towards HIV-infected people: fear or help? Vestnik Dermatologii i Venerologii. 2019; 95 (4): 40—47. https://doi.org/10.25208/0042-4609-2019-95-4-40-47 (Russia).]

2. Хрянин А.А., Решетников О.В., Шпикс Т.А., Русских М.В., Коваленко Г.А., Маринкин И.О. Знания и информированность молодых людей о ВИЧ/СПИД и особенности их полового поведения. Вестник дерматологии и венерологии. 2018; 94 (5): 59—65. https:// doi.org/10.25208/0042-4609-2018-94-5-59-65. [Khryanin A.A., Reshetnikov 0.V., Shpiks T.A., Russkih M.V., Kovalenko G.A., Marinkin I.0. HIV/AIDS awareness among young people and their sexual behavior. Vestnik Dermatologii i Venerologii. 2018; 94 (5): 59—65. https://doi. org/10.25208/0042-4609-2018-94-5-59-65 (Russia).]

3. Martin-Smith H.A., Okpo E.A., Bull E.R. Exploring psychosocial predictors of STI testing in University students-BMC Public Health. 2018; 18: 664.

4. Habel M.A., Haderxhanaj L., Hogben M., Eastman-Mueller H., Chesson H., Roberts C.M. Does your college campus GYT? Evaluating the effect of a social marketing campaign designed to raise STI awareness and encourage testing. Cases Public Health Commun Mark. 2015 winter; 8: $51-70$. 


\section{Информация об авторах}

Алексей Алексеевич Хрянин - д.м.н., профессор кафедры дерматовенерологии и косметологии ФГБОУ ВО «Новосибирский государственный медицинский университет» Минздрава России, вице-президент РОО «Ассоциация акушеров-гинекологов и дерматовенерологов»; e-mail: khryanin@mail.ru; ORCID: orcid.org/0000-0001-9248-8303

Татьяна Александровна Шпикс - к.М.Н., доцент кафедры педагогики и психологии ФГБОУ ВО «Новосибирский государственный медицинский университет» Минздрава России

Мария Викторовна Русских - аспирант кафедры дерматовенерологии и косметологии ФГБОУ ВО «Новосибирский государственный медицинский университет» Минздрава России

Валентина Константиновна Бочарова - студентка 6-го курса педиатрического факультета ФГБОУ ВО «Новосибирский государственный медицинский университет» Минздрава России

\section{Information about the authors}

Aleksey A. Khryanin — Doctor of Medical Sciences, Professor of the Department of Dermatovenereology and Cosmetology of the Novosibirsk State Medical University under the Ministry of Health of Russian Federation, Vice President of the Association of Obstetricians-Gynecologists and Dermatovenereologists; e-mail: khryanin@mail.ru; ORCID: orcid.org/0000-0001-9248-8303

Tatyana A. Shpiks - Candidate of Medical Sciences, Associate Professor of the Department of Pedagogy and Psychology, Novosibirsk State Medical University under Ministry of Health of Russian Federation

Maria V. Russkikh - Postgraduate student of the Department of Dermatovenereology and Cosmetology, Novosibirsk State Medical University under Ministry of Health of Russian Federation

Valentina K. Bocharova - Student of the sixth year of the Medical Department of the FSBEl of Higher Education "Novosibirsk State Medical University" under the Ministry of Healthcare of the Russian Federation 